\title{
Effect of pre-aging deformation on the intergranular corrosion resistance of 6000 series aluminium alloys
}

\author{
Otto Lunder ${ }^{1,2^{*}}$, Julie Grønvold ${ }^{2}$, Calin Daniel Marioara ${ }^{1}$, Sigurd Wenner ${ }^{1}$, and Trond Furu Fu $^{2,3}$ \\ ${ }^{1}$ SINTEF Industry, NO-7465 Trondheim, Norway \\ ${ }^{2}$ Norwegian University of Science and Technology, NO-7491 Trondheim, Norway \\ ${ }^{3}$ Norsk Hydro ASA, NO-0283 Oslo, Norway
}

\begin{abstract}
Aluminium alloys in the 6000 series may become susceptible to intergranular corrosion (IGC) by unfavourable thermomechanical processing in combination with presence of $\mathrm{Cu}$ and a low $\mathrm{Mg} / \mathrm{Si}$ ratio. The IGC susceptibility has been related to the segregation of $\mathrm{Cu}$ during artificial ageing to form a nearly continuous $\mathrm{Cu}$ film along the grain boundaries with an anodic solute depleted zone adjacent to it. In this work, extruded alloys 6005 and C28 as well as two variants of 6016 automotive sheet were subjected to various degrees of deformation by rolling or stretching before artificial aging. Accelerated IGC testing showed that pre-deformation significantly improved the IGC resistance of the $\mathrm{Cu}$ containing extruded alloys, while no improvement was observed for the 6016 sheet materials containing $<0.01 \mathrm{wt} \% \mathrm{Cu}$. High resolution scanning transmission electron microscopy (STEM) of pre-deformed 6005 alloy showed precipitation of $\mathrm{Cu}$-containing Q' phase on dislocations. As a result, the amount of $\mathrm{Cu}$ available for diffusion to the grain boundaries is reduced, which might explain why a beneficial effect of pre-deformation on the IGC resistance was observed only for the $\mathrm{Cu}$-containing materials.
\end{abstract}

\section{Introduction}

Heat treatable 6000 series aluminium alloys have several attractive properties but may become susceptible to intergranular corrosion as a result of unfavourable thermomechanical treatment or alloying [1-3]. In a series of papers, Svenningsen et al. [4-6] and Larsen et al. [7, 8] showed the importance of heat treatment on the IGC resistance of 6000 series alloys with low $\mathrm{Cu}$ content. The presence of $\mathrm{Cu}$ increased the IGC susceptibility as a result of aging by forming a continuous $\mathrm{Cu}$ film and noble Q-phase $\left(\mathrm{Al}_{5} \mathrm{Cu}_{2} \mathrm{Mg}_{8} \mathrm{Si}_{6}\right)$ precipitates along the grain boundaries and a precipitate free zone (PFZ) depleted in $\mathrm{Cu}$ and $\mathrm{Si}$ adjacent to it. The depletion of $\mathrm{Cu}$ and $\mathrm{Si}$ in the PFZ is expected to form a continuous anodic path along the grain boundaries, thus providing micro-galvanic coupling as the local driving force for IGC propagation. These results were recently confirmed by Kairy et al. [9, 10] who combined STEM and atom probe tomography (APT) to verify the existence of a $\mathrm{Cu}$ "wetting layer", estimated to be about $2 \mathrm{~nm}$ in thickness, along the grain boundaries. The role of $\mathrm{Si} / \mathrm{Mg}$ ratio, $\mathrm{Cu}$ content and aging condition on IGC resistance and hardness was further reviewed through a systematic investigation of nine custom made 6000 series alloy. Based on this work, a generalized microstructure-based model for IGC susceptibility was proposed [10].

Additional progress in understanding initiation and propagation of IGC was made by Kumari et al. [11, 12]. In particular, it was shown that $\mathrm{Cu}$ enriches continuously by dealloying at corroding sites and becomes the dominating cathode both at the external surface and in the interior IGC filaments.

In general, results from previous studies indicate that even slight variations in alloy composition (particularly $\mathrm{Cu}$ content and $\mathrm{Si} / \mathrm{Mg}$ ratio) and thermomechanical processing can significantly affect the susceptibility to IGC. Extruded profiles are often straightened or subjected to different forms of deformation before age hardening, which changes the precipitation kinetics. Earlier work [13] showed that predeformation reduced the time to reach maximum yield strength during artificial aging. Moreover, the precipitates formed in the pre-deformed material were coarser, with a lower number density but higher volume fraction than in the undeformed material.

Results from a recent study [14] indicated a significant improvement of the IGC resistance of an AA6005A alloy containing $0.14 \mathrm{wt} \% \mathrm{Cu}$ by including a pre-deformation step before aging. High resolution STEM imaging showed that the pre-deformation caused $\mathrm{Cu}$ containing precipitates to nucleate at dislocation lines. Furthermore, pre-deformation resulted in a higher amount of $\mathrm{Cu}$ locked into bulk precipitates than in the undeformed material. Hence, the results indicated a correlation between increased $\mathrm{Cu}$ absorption into precipitates, reduced $\mathrm{Cu}$ concentration at the grain boundaries and an improved IGC resistance [14]. The purpose of the present work is to further verify the effect of pre-deformation on the IGC resistance by examining a

\footnotetext{
* Corresponding author: Otto.Lunder@sintef.no
} 
few 6000 series aluminium alloys with different $\mathrm{Cu}$ content and $\mathrm{Si} / \mathrm{Mg}$ ratio.

\section{Experimental}

\subsection{Materials}

Table 1 shows the chemical composition of the materials investigated. Extruded 6005 alloy profiles (150 mm x 3.9 $\mathrm{mm})$ supplied by Hydro were solution heat treated at $540^{\circ} \mathrm{C}$ for $30 \mathrm{~min}$, water quenched and pre-deformed 1 , 5 and $10 \%$ by rolling or stretching, respectively, before ageing at $185^{\circ} \mathrm{C}$ for $5 \mathrm{~h}$. The $\mathrm{C} 28$ alloy was cast into 95 $\mathrm{mm}$ billets at Hydro, homogenized at $575^{\circ} \mathrm{C}$ for $2 \mathrm{~h}$ and extruded to $25 \mathrm{~mm} \times 3.9 \mathrm{~mm}$ profiles in an $8 \mathrm{MN}$ laboratory press at SINTEF, then solution heat treated at $540^{\circ} \mathrm{C}$ for $30 \mathrm{~min}$, water quenched, pre-deformed and aged under similar conditions as the 6005 alloy, cf. Figure 1a. In addition, a separate series of 6005 and C28 specimens were deformed 1,5 and $10 \%$ by rolling or stretching after ageing (instead of before ageing); these are referred to as post-deformed. Figure $1 \mathrm{~b}$ shows the thermomechanical processing of the two variants (denoted A and B) of $1 \mathrm{~mm}$ thick 6016 automotive sheet. After solution heat treatment at $560^{\circ} \mathrm{C}$ for $5 \mathrm{~min}$, the materials were cooled by forced air, pre-baked at $90^{\circ} \mathrm{C}$ for $24 \mathrm{~h}$, stored for at least one week at room temperature, pre-deformed and finally aged at $185^{\circ} \mathrm{C}$ for $20 \mathrm{~min}$ to simulate a paint bake cycle.

Table 1. Composition (wt\%) of the test materials.

\begin{tabular}{|c|c|c|c|c|c|c|}
\hline Alloy & Si & Fe & Cu & Mn & Mg & Cr \\
\hline 6005 & 0.62 & 0.19 & 0.15 & 0.16 & 0.56 & $<0.001$ \\
\hline C28 & 0.72 & 0.20 & 0.20 & 0.51 & 0.83 & 0.16 \\
\hline $6016 \mathrm{~A}$ & 1.49 & 0.19 & 0.002 & 0.078 & 0.38 & 0.001 \\
\hline $6016 \mathrm{~B}$ & 1.33 & 0.20 & 0.010 & 0.064 & 0.30 & 0.004 \\
\hline
\end{tabular}

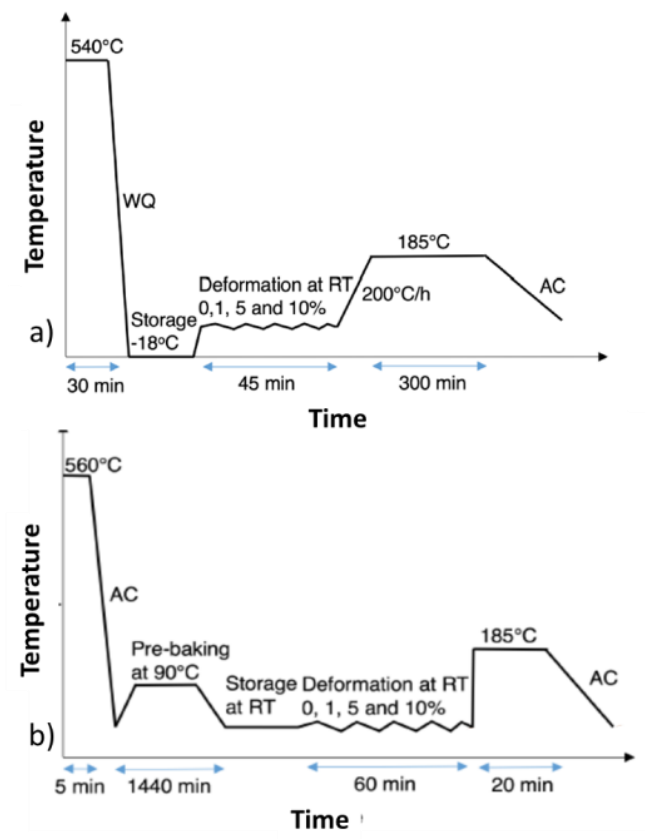

Figure 1. Thermo-mechanical processing of alloys a) 6005 and C28, b) $6016 \mathrm{~A}$ and $6016 \mathrm{~B}$.

\subsection{Intergranular corrosion testing}

IGC testing was performed according to the ISO 11846 (method B) standard. The procedure included cleaning of $25 \mathrm{~mm}$ x $20 \mathrm{~mm}$ size samples by immersion for $3 \mathrm{~min}$ in $7.5 \% \mathrm{NaOH}$ solution at $50-60^{\circ} \mathrm{C}$, followed by desmutting in concentrated nitric acid for $2 \mathrm{~min}$, rinsing in water and drying. The IGC test involved immersion in an acidified salt solution $(3 \mathrm{wt} \% \mathrm{NaCl}+1 \mathrm{vol} \% \mathrm{HCl})$ for $24 \mathrm{~h}$. The ratio of the solution volume to the total sample surface area was kept constant at $20 \mathrm{ml} / \mathrm{cm}^{2}$ for all tests. After IGC testing, the samples were rinsed under running water, immersed in concentrated nitric acid for 2 min to remove corrosion products, rinsed in distilled water and air dried. All samples were weighed before and after IGC testing to assess the mass loss caused by corrosion.

\subsection{Microstructure characterization}

Corrosion tested samples were cut along the fabrication direction, mounted in epoxy resin, ground and polished, and the cross-section area examined by use of a Leica MEF4M optical microscope to assess the extent, type and maximum depth of localised attacks. Vickers hardness measurements were performed on a Zwick Roell Indentec hardness testing machine, using a load of $1 \mathrm{~kg}$ and loading time of $15 \mathrm{~s}$ on the as-manufactured surface. High resolution scanning transmission electron microscope (STEM) images of the precipitate microstructure and grain boundaries were acquired by use of a JEOL ARM $200 \mathrm{~F}$ operating at $200 \mathrm{kV}$. Thin foil samples from a region close to the original surface were electropolished using a Struers TenuPol-5 unit, with a $1 / 3$ nitric acid $+2 / 3$ methanol electrolyte.

\section{Results}

\subsection{Grain structure and hardness}

Figure 2 shows optical micrographs of the undeformed grain structure of the alloys. All materials were fully recrystallized as a result of solution heat treatment. However, the materials exhibited significant differences in grain size. The hardness of aged alloys 6005 and C28 was about $100 \mathrm{HV}$ and $112 \mathrm{HV}$, respectively, practically independent of the degree of pre-deformation (results not shown). For both the 6016 sheets, the hardness after aging increased from about $82 \mathrm{HV}$ for the undeformed material to $96 \mathrm{HV}$ for the $10 \%$ deformed material.

\subsection{Accelerated IGC testing}

Metallographic cross section images from representative locations on IGC tested samples are shown in Figure 3. The undeformed 6005 alloy sample (Figure 3a) exhibited uniform IGC, characterized by narrow and knife-edge sharp attacks along all the grain boundaries at the surface. The $1 \%$ pre-deformed sample showed a similar behaviour. However, pre-deformation to $5 \%$ or $10 \%$ (Figure $3 \mathrm{~b}$ ) considerably reduced the extent of IGC. 
Attacks became more localised and a there was a significant decrease in penetration depth compared to the undeformed material. A similar effect of predeformation was also observed for the $\mathrm{C} 28$ alloy. While $1 \%$ pre-deformation had little effect, a $5 \%$ or $10 \%$ predeformation by rolling changed the corrosion morphology from IGC to pitting (Figure $3 \mathrm{c}$ and $3 \mathrm{~d}$ ).
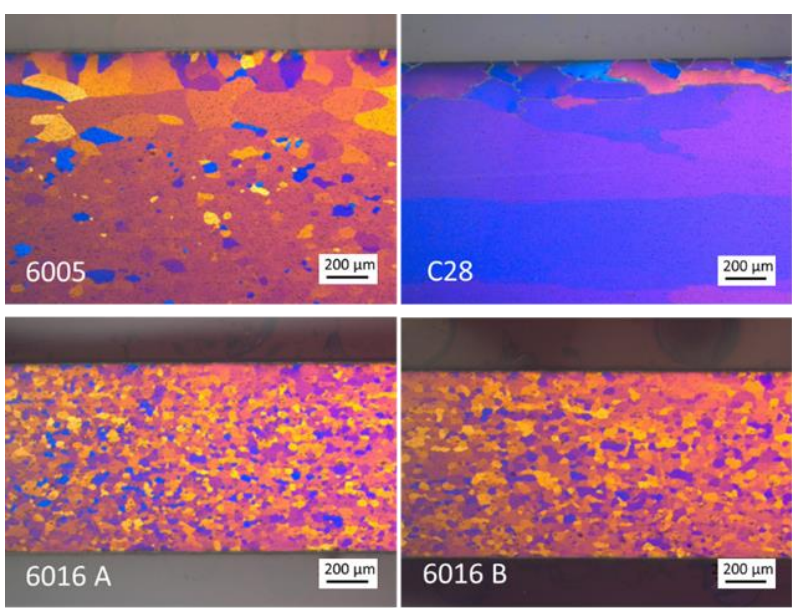

Figure 2. Grain structure of the alloys in longitudinal cross section.
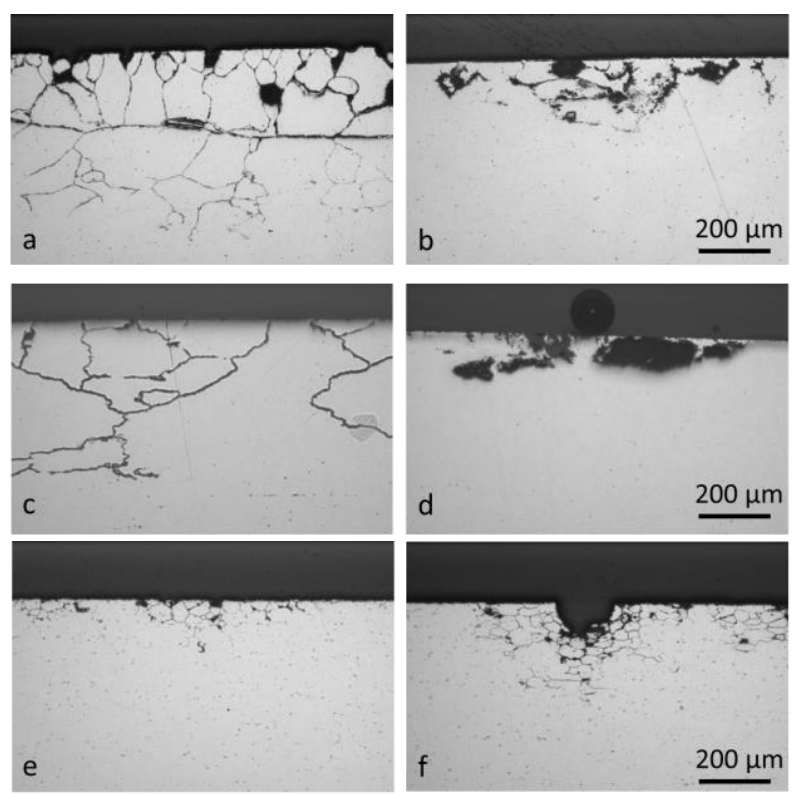

e
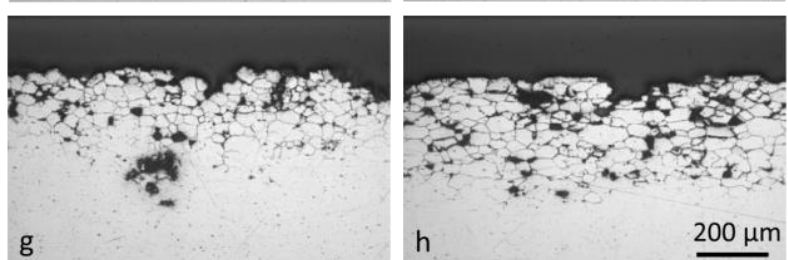

Figure 3. Cross section micrographs of the most severe attacks on undeformed (a, c, e, g) and 10\% pre-rolled (b, $\mathrm{d}, \mathrm{f}, \mathrm{h})$ samples after IGC testing: a, b) 6005 , c, d) C28, e, f) $6016 \mathrm{~A}, \mathrm{~g}, \mathrm{~h}) 6016 \mathrm{~B}$.

Contrary to the above results, pre-deformation of the $6016 \mathrm{~A}$ (Figure 3e and 3f) and $6016 \mathrm{~B}$ (Figure 3g and $3 \mathrm{~h}$ ) alloys had no beneficial effect on the corrosion behaviour. In fact, pre-deformation of the 6016 A alloy resulted in an increased susceptibility to IGC. The weight loss also doubled relative to the undeformed material. For the $6016 \mathrm{~B}$ alloy, very high corrosion rate and severe IGC occurred over the entire sample surface, independent of the degree of pre-deformation. The effect of pre-deformation on the maximum penetration depth after IGC testing is shown for all samples in Figure 4.

Samples deformed up to $10 \%$ by rolling or stretching after aging showed no significant change in IGC susceptibility relative to the undeformed 6005 and C28 samples. Figure 5 shows cross section micrographs of $10 \%$ post-deformed and IGC tested 6005 and C28 alloy samples. All post-deformed samples showed similar corrosion morphology as the undeformed material. Maximum depth of IGC attack and corrosion rate (determined from weight loss measurements) were also practically unaffected by post-deformation processing.
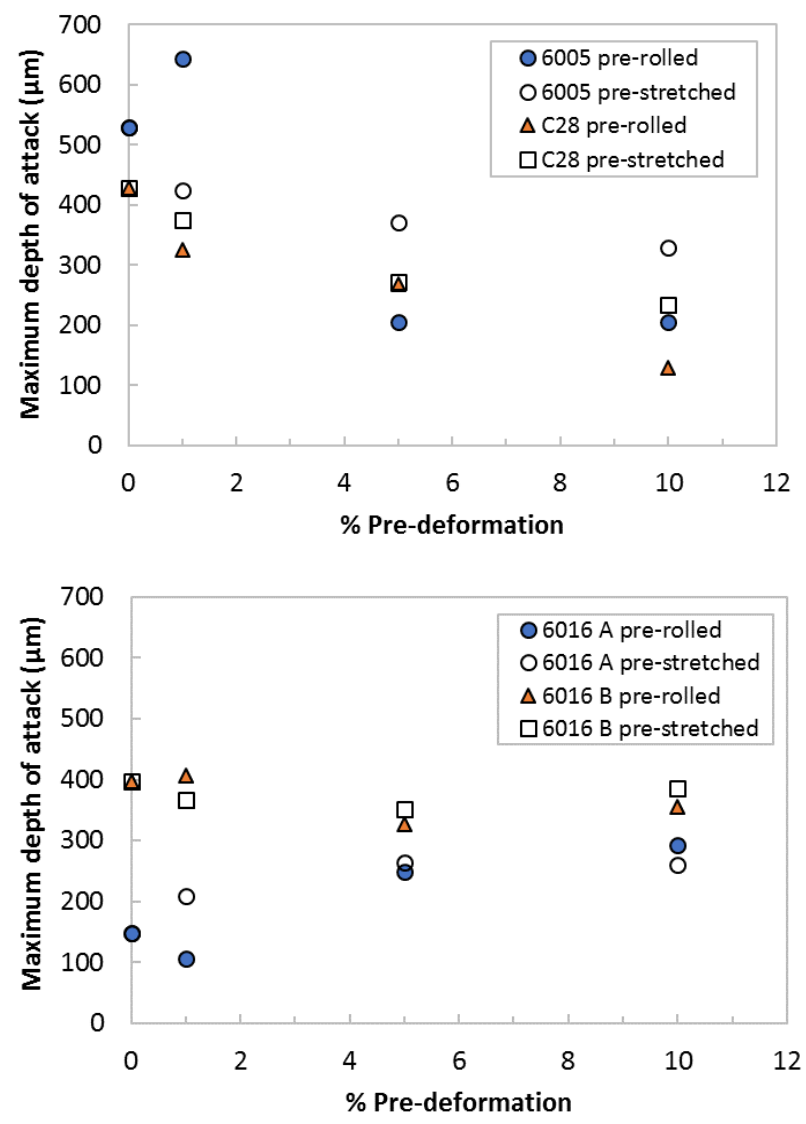

Figure 4. Influence of the degree of pre-aging deformation on the maximum depth of localised corrosion attack of IGC tested samples.

\subsection{TEM characterization}

TEM analysis of alloy 6005 in the undeformed and 10\% pre-rolled condition showed a homogeneous bulk precipitate distribution in the undeformed material (Figure 6a), while in the pre-deformed material precipitation was more inhomogeneous and occurred preferentially on dislocation lines (Figure $6 \mathrm{~b}$ and $6 \mathrm{c}$ ), as expected. High-angle annular dark-field imaging 
(HAADF) STEM images are shown in Figure 6d-e, with $\mathrm{Cu}$ atomic columns appearing bright, and $\mathrm{Al} / \mathrm{Mg} / \mathrm{Si}$ columns appearing darker.

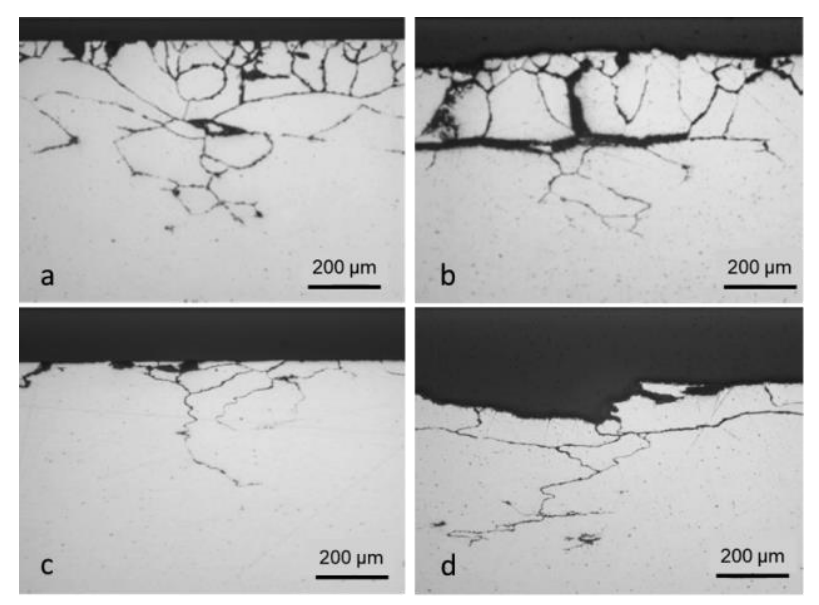

Figure 5. Cross section micrographs of IGC tested alloys 6005 (a, b) and C28 (c, d), deformed $10 \%$ by rolling $(a, c)$ or stretching $(b, d)$ after artificial aging.
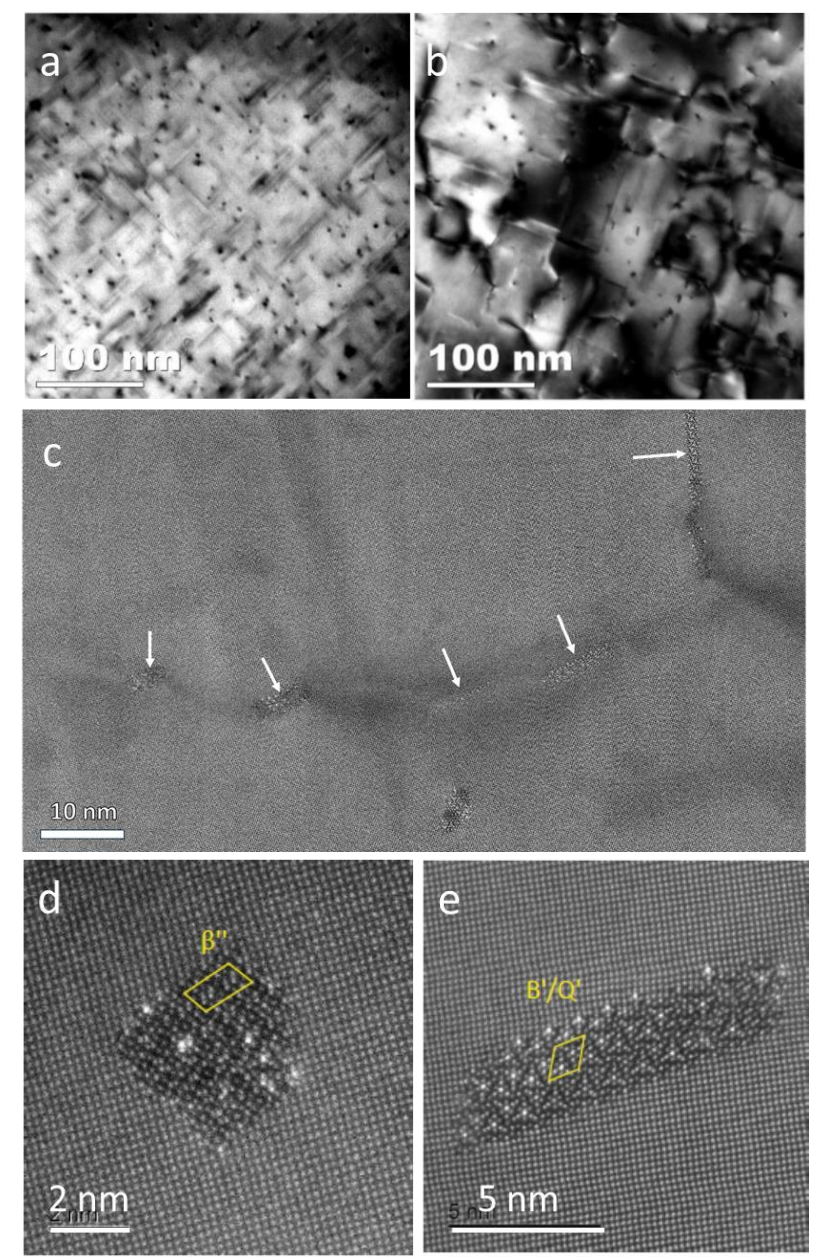

Figure 6. Bright field TEM overview images of a) undeformed and b) $10 \%$ pre-rolled 6005 alloy aged for 5 $\mathrm{h}$ at $185^{\circ} \mathrm{C}$; c) HAADF-STEM image of Cu-containing precipitates nucleated along dislocation line (arrows) in the pre-deformed material; and individual precipitates in the d) undeformed and e) pre-deformed material.
Most of the precipitates in the undeformed material were disordered $\beta$ " particles with low $\mathrm{Cu}$ content (Figure $6 \mathrm{~d})$. In the pre-deformed condition dislocations were present, which nucleate coarser, more ordered and more $\mathrm{Cu}$-rich Q' precipitates (Figure 6e). The density of dislocations increases with degree of deformation, leading to a higher fraction of the heterogeneously nucleated kind of precipitates [14].

Although precipitate statistics was not presently made for the pre-deformed material, earlier work [13] on alloy 6060 has shown that pre-deformation results in a lower number density but higher precipitate volume fraction than in undeformed material. Hence, based on the present and earlier findings it seems clear that under similar aging conditions pre-deformation causes more $\mathrm{Cu}$ to become incorporated in precipitates than in the undeformed material. However, STEM/EDS element mapping (results not shown here) indicated that a continuous $\mathrm{Cu}$ film still formed along some of the grain boundaries in the pre-deformed material. $\mathrm{Cu}$ also segregated to interfaces between the $\mathrm{Al}$ matrix and $\mathrm{Fe}-$ rich primary particles.

\section{Discussion}

The present work confirms and supplements earlier results [14] showing a beneficial effect of predeformation on the IGC resistance of 6000 series alloys with low $\mathrm{Cu}$ content. Results revealed that deformation of the $\mathrm{Cu}$ containing 6005 and $\mathrm{C} 28$ alloys by rolling or stretching before aging significantly reduced the IGC susceptibility of these materials. It was further shown that the dislocations introduced by the pre-deformation acted as heterogeneous nucleation sites for precipitation of $\mathrm{Cu}$-containing Q' phase particles, in accordance with previous findings $[13,14]$. The increased amount of $\mathrm{Cu}$ locked in precipitates in the pre-deformed material implies that the amount of $\mathrm{Cu}$ available for diffusion to form a $\mathrm{Cu}$ film and cathodic precipitates along the grain boundaries is reduced, which should contribute to reduced IGC susceptibility. The results obtained for alloys 6005 and C28 (Figure 4) indicate that a 5\% predeformation is enough to significantly reduce the maximum depth of IGC attacks after accelerated testing. Pre-rolling appeared to be more efficient than prestretching in reducing the penetration depth, possibly related to differences in the deformation distribution across the material thickness.

Extensive evidence from previous studies [4-10] suggests that the IGC susceptibility of the 6005 and C28 alloys can be ascribed to the formation of a continuous $\mathrm{Cu}$ film and cathodic $\mathrm{Q}$ phase precipitates along the grain boundaries, accompanied by an adjacent solute depleted PFZ which constitute the anodic path for IGC. Evidently, the introduction of dislocations before aging modified the precipitate microstructure and local distribution positively with respect to IGC. However, deformation applied after aging caused no change in corrosion behaviour relative to the undeformed materials, demonstrating that the presence of 
dislocations per se had negligible influence on the corrosion mechanism.

Since pre-deformation results in coarser precipitates with a higher volume fraction than in undeformed material [13], the precipitate structure might be regarded more like that of an overaged material. It has been observed [5] that $\mathrm{AlMgSi}(\mathrm{Cu})$ alloys may become susceptible to pitting in overaged temper due to coarsening of matrix precipitates and solute depletion of the bulk matrix. The Al matrix then becomes more similar to the PFZ in composition and the preferred pathway for anodic dissolution, i.e. the PFZ, becomes less distinct. The transition from IGC to pitting with increasing degree of pre-deformation was particularly observed for the C28 alloy (Figure 3d). Moreover, the improved corrosion resistance of alloys 6005 and C28 by pre-deformation was obtained without any significant change in hardness. Apparently, the work hardening introduced by rolling or stretching compensated for the coarser precipitate structure formed by aging of the predeformed material.

Pre-deformation of the 6016 alloys did not influence the IGC susceptibility much, which is consistent with the above hypothesis since these materials were practically $\mathrm{Cu}$ free but have a very high $\mathrm{Si} / \mathrm{Mg}$ ratio to enable adequate hardening during a paint baking cycle. For these alloys, the IGC susceptibility is probably controlled mainly by the excess $\mathrm{Si}$ rather than the presence of a small amount of impurity $\mathrm{Cu}$. It is well known $[8,10]$ that the severity of IGC increases with an increase in the $\mathrm{Si} / \mathrm{Mg}$ ratio of 6000 series alloys, related to the formation of a Si-depleted zone adjacent to the grain boundaries after aging [10]. However, as seen from Figures 3 and 4, the $6016 \mathrm{~B}$ material was clearly inferior to $6016 \mathrm{~A}$ in the IGC test despite a relatively small difference in $\mathrm{Si} / \mathrm{Mg}$ ratio between the two. The effective $\mathrm{Si} / \mathrm{Mg}$ ratio in $6016 \mathrm{~A}$ and $6016 \mathrm{~B}$ was estimated to be 3.7 and 4.1, respectively, when subtracting the amount of $\mathrm{Si}$ incorporated into Fe-containing primary particles and dispersoids. In addition to a slightly higher $\mathrm{Si} / \mathrm{Mg}$ ratio, 6016 B contained more $\mathrm{Cu}(0.010 \%)$ than $6016 \mathrm{~A}$ $(0.002 \%)$. Hence, it cannot be ruled out that the presence of very low $\mathrm{Cu}$ concentrations contribute to the IGC susceptibility in alloys with high $\mathrm{Si} / \mathrm{Mg}$ ratio. Work is in progress to further understand the role of $\mathrm{Cu}$ and $\mathrm{Si} / \mathrm{Mg}$ ratio in 6016 alloys.

\section{Conclusion}

The IGC resistance of extruded AlMgSi alloys with low $\mathrm{Cu}$ content can be considerably improved by predeforming the material $5-10 \%$ before aging, with minimal change in hardness. The favourable effect of pre-deformation on corrosion properties is attributed to an increased amount of $\mathrm{Cu}$ locked in precipitates nucleated on dislocation lines in the pre-deformed microstructure, causing less $\mathrm{Cu}$ to be available for diffusion to the grain boundaries. Pre-deformation did not improve the IGC resistance of $\mathrm{Cu}$-free $(<0.010 \%)$ sheet materials with very high $\mathrm{Si} / \mathrm{Mg}$ ratio, where IGC susceptibility is associated with Si depletion adjacent to the grain boundary.

\section{Acknowledgements}

This work was performed as part of the Norwegian national project entitled, Fundamentals of Intergranular Corrosion in Aluminium Alloys (FICAL), supported by The Research Council of Norway (contract no. 247598), Hydro, Gränges, Benteler Automotive Raufoss and Steertec Raufoss. The (S)TEM work was conducted on the NORTEM (NFR: 197405) infrastructure at the TEM Gemini Centre, Trondheim, Norway.

\section{References}

1. H. P. Godard, W.B. Jepson, M.R. Bothwell, R.L. Kane, The Corrosion of Light Metals (John Wiley, New York, 1967).

2. L. F. Mondolfo, Aluminium Alloys: Structure and Properties (Butterworths, London, 1976).

3. J. E. Hatch, Aluminium - Properties and Physical Metallurgy (American Society for Metals, Ohio, 1984).

4. G. Svenningsen, J. E. Lein, A. Bjørgum, J. H. Nordlien, Y. Yu, K. Nisancioglu, Corros. Sci., 48, 226 (2006).

5. G. Svenningsen, M. H. Larsen, J. C. Walmsley, J. H. Nordlien, K. Nisancioglu, Corros. Sci., 48, 1528 (2006).

6. G. Svenningsen, M. H. Larsen, J. H. Nordlien, K. Nisancioglu, Corros. Sci., 48, 3969 (2006).

7. M. H. Larsen, J. C. Walmsley, O. Lunder, R. H. Mathiesen, K. Nisancioglu, J. Electrochem. Soc., 155, C550 (2008).

8. M. H. Larsen, J. C. Walmsley, O. Lunder, K. Nisancioglu, J. Electrochem. Soc., 157, C61 (2010).

9. S. K. Kairy, T. Alam, P. A. Rometsch, C. H. J. Davies, R. Banerjee, N. Birbilis, Metall. Mat. Trans. A, 47A, 985 (2016).

10. S. K. Kairy, P. A. Rometsch, C. H. J. Davies, N. Birbilis, Corrosion, 73, 1280 (2017).

11. S. Kumari, S. Wenner, J. C. Walmsley, O. Lunder, K. Nisancioglu, J. Electrochem. Soc., 166, C3114 (2019).

12. S. Kumari,S. Wenner, J. C. Walmsley, O. Lunder, K. Nisancioglu, Corros. Sci., 158, 108090 (2019).

13. K. Teichmann, C. D. Marioara, S. Andersen, K. Marthinsen, Metall. Mat. Trans. A, 43A, 4006 (2012).

14. C. D. Marioara, A. Lervik, J. Grønvold, O. Lunder, S. Wenner, T. Furu, R. Holmestad, Metall. Mat. Trans. A, 49, 5146 (2018). 